\title{
Immunoglobulin A Measurement
}

National Cancer Institute

\section{Source}

National Cancer Institute. Immunoglobulin A Measurement. NCI Thesaurus. Code C81969.

The determination of the amount of immunoglobulin A present in a sample. 